\title{
Cost optimization and flexibility analysis for the liquefaction of an associated natural gas stream
}

Eini, Saeed; Kontogeorgis, Georgios M.; Rashtchian, Davood

Published in:

Journal of Energy Resources Technology

Link to article, DOI:

$10.1115 / 1.4045459$

Publication date:

2020

Document Version

Peer reviewed version

Link back to DTU Orbit

Citation (APA):

Eini, S., Kontogeorgis, G. M., \& Rashtchian, D. (2020). Cost optimization and flexibility analysis for the liquefaction of an associated natural gas stream. Journal of Energy Resources Technology, 142(6), [JERT-191723]. https://doi.org/10.1115/1.4045459

\section{General rights}

Copyright and moral rights for the publications made accessible in the public portal are retained by the authors and/or other copyright owners and it is a condition of accessing publications that users recognise and abide by the legal requirements associated with these rights.

- Users may download and print one copy of any publication from the public portal for the purpose of private study or research.

- You may not further distribute the material or use it for any profit-making activity or commercial gain

- You may freely distribute the URL identifying the publication in the public portal 
3 Cost optimization and flexibility analysis for the liquefaction of an associated natural gas stream

\section{5}

$8{ }^{a}$ Chemical and Petroleum Engineering Department, Sharif University of Technology, Tehran, Iran

9 ' ${ }^{\mathrm{b}}$ Department of Chemical and Biochemical Engineering, Technical University of Denmark, DK-2800 Lyngby, 10 Denmark

* Corresponding author: Department of Chemical and Petroleum Engineering, Sharif University of Technology, Azadi Ave., Tehran, Iran. E-mail address: rashtchian@sharif.edu, Tel: 00982166165050 


\section{Abstract}

13 Liquefaction and then transportation to the market is one of the promising options for the utilization

14 of associated natural gas resources which are produced in oil fields. However, the flow of such

15 resources is normally unsteady. Additionally, the associated gas in one oil field may exhaust in a few

16 years and the liquefaction plant should be moved to another oil field with different specifications. In

17 order to tackle such challenges, liquefaction systems not only must be optimally designed and

18 operated, but also they should be flexible with respect to the gas flow fluctuations. The flexibility

19 analysis of such processes is usually ignored in the optimization studies. In this research, first, the

20 economic performance of two small-scale liquefaction processes (a Single Mixed-Refrigerant

21 process, SMR, and a nitrogen expander process) were optimized and compared. The results showed

22 that the SMR process is economically more attractive (49\% lower lifecycle cost compared to the

23 nitrogen expander process). As a post-optimization step, flexibility analysis was performed to

24 investigate the ability of optimal designs in overcoming gas flow fluctuations. For this purpose, five-

25 thousand feed samples with different flowrate and methane content were supposed which formed a

26 feasibility-check region. The results showed that with respect to the design constraints, the optimal

27 SMR process is more flexible and feasibly operates in the entire region. However, the nitrogen

28 expander process cannot feasibly operate for the gas feed with high flowrate and low methane content.

30 Keywords: Associated Gas; LNG Process; Process Optimization; Equation-Oriented; Flexible 31 process 


\section{1. Introduction}

34 The improving living standards and growing population result in the increasing demand of energy.

35 Natural gas, viewed as a cleaner alternative to other fossil fuels in terms of acidic and greenhouse gas

36 emissions, provides an attractive option in order to fulfill this growing demand [1]. In comparison to

37 the demand for coal and oil, the natural gas demand is increasing rapidly and it is also expected that

38 the investment to find new natural gas reserves across the globe will increase in near future [2].

39 Associated natural gas (ANG) is one of the natural gas resources which is produced as a byproduct

40 in oil fields. ANG is usually flared or vented, contributing a major part in global greenhouse gas

41 emissions [3]. Therefore, the appropriate management of such resources has a very high priority not

42 only with respect to environmental issues but also for monetizing them as energy sources.

43 Pipeline transmission is the most common transportation option for non-associated natural gases [4].

44 However, it is inflexible with respect to the transmission capacity and requires huge initial

45 construction cost, and it is a large burden for small and offshore gas resources such as ANG [5].

46 Liquefied Natural Gas (LNG) is an energy carrier preferred over pipeline transmission for such

47 resources [6,7]. The produced LNG can be transmitted and used in many industries including as the

48 fuel of advanced combined power plants which have enhanced thermal efficiency [8] and as an

49 alternative transportation fuel [9].

50 Among various types of liquefaction processes, nitrogen expander process and Single-stage Mixed-

51 Refrigerant (SMR) process have been considered as the suitable liquefaction process for small-scale and offshore LNG platforms [10]. These processes have relatively simple configuration, require low

53 capital investment, and provide quick start-up and shut-down [10,11]. The difference among these

54 processes is mainly related to their construction and operating costs. Nitrogen expander processes are

55 extremely compact and inherently safe to operate [11]. Compared to other technologies, they usually

56 require small heat transfer area for the main heat exchanger (MHEX). However, they have a very

57 high specific power demand (shaft work per produced amount of LNG). In SMR processes, a mixture Assigned paper number: JERT-19-1723 
58 of nitrogen and light hydrocarbons are usually utilized as the refrigerant which evaporates over a

59 similar range as natural gas. Therefore, they provide a close match between hot and cold composite

60 curves in the MHEX and this ultimately reduces the power consumption [4]. It should be noted that

61 in liquefaction processes, there is always a trade-off between power consumption and total heat

62 exchanger surface area. Castillo and Dorao [11] have thoroughly compared pros and cons of different

63 small-scale LNG technologies.

64 Qyyum et al. [2], He et al. [10], and Austbø et al. [12] have comprehensively reviewed the different

65 aspects of the studies concerning LNG process design and optimization. Although LNG is a

66 promising option for the management of ANG, the liquefaction process is energy intensive. The main

67 contribution to energy consumption is the power consumption required by the compressor system.

68 Due to this fact, most research activities have focused on the optimization of required power in

69 liquefaction systems. In the following, several representative studies regarding the optimization of

70 liquefaction process for associated natural gas and small-scale applications are reviewed.

71 Yin et al. [13] optimized two types of natural gas liquefaction processes (SMR and nitrogen expander)

72 for small-scale applications. In their study the SMR process showed better performance in terms of

73 both energy consumption and economics [13].

74 Shirazi and Mowla [14] optimized the power consumption of an SMR process for a peak shaving

75 plant. Additionally, they evaluated the exergy efficiency of the equipment in the process. They

76 concluded that the majority part of exergy loss occurs in the compression stages [14].

$77 \mathrm{He}$ and $\mathrm{Lu}[15]$ presented and optimized a novel process for small-scale natural gas liquefaction. The

78 proposed process utilizes the pressure exergy of the pipeline to liquefy a part of natural gas without

79 any energy consumption. Although this process has zero energy consumption, it can liquefy a small

80 portion of the natural gas stream, and the majority of the gas remains in the gaseous form [15]. 
$81 \mathrm{He}$ and $\mathrm{Ju}[16]$ proposed and optimized a nitrogen expansion liquefaction process for an associated

82 natural gas stream. Then, they tested the performance of the process using two different gas streams

83 while fixing the process parameters as the baseline case. They concluded that the optimized process

84 can also liquefy the new gas streams. Moreover, compared with two other nitrogen expansion

85 processes, they showed that the proposed configuration has better performance in term of energy

86 efficiency [16].

87 Yuan et al. [17] proposed and optimized a nitrogen expansion process with carbon dioxide pre-

88 cooling. They investigated the exergy loss of the equipment and concluded that the compressor

89 system causes the majority part of the exergy losses. In addition, they studied the effect of the natural

90 gas feed condition on the energy performance of the process. They showed that the specific energy

91 consumption is reduced as the feed gas pressure increases. On the other hand, increasing the feed

92 temperature and methane content result in higher specific energy consumption [17].

93 Aslambakhsh et al. [18] optimized the lifecycle cost of a mini-scale SMR process. They investigated

94 the effects of the process parameters (such as the refrigerant flowrate and inlet/outlet pressure levels

95 of the compressors) on the plant lifecycle cost [18].

96 The abovementioned studies have mainly focused on the energetic analysis of liquefaction processes.

97 However, in addition to the energy efficiency, the flexibility of liquefaction processes should be

98 evaluated and analyzed. It is a crucial issue specially for associated gas produced in oil fields, because

99 the gas flow is normally unsteady in such fields. Moreover, the associated gas in one oil field may

100 exhaust in a few years. Therefore, the LNG plant should be moved to another oil field to produce

101 LNG with different gas conditions [16]. Therefore, it is essential to analyze whether the liquefaction

102 process is flexible enough to operate under different feed conditions.

103 Process flexibility analysis was introduced with the goal of evaluating robust and flexible process

104 design [19-21]. Flexibility analysis can be used to quantify the extent to which the uncertainty or Assigned paper number: JERT-19-1723 
105 changes in parameters are tolerated by a particular process design [22]. In other words, if a process

106 remains feasible over a pre-defined range of potential deviations in process parameters, it could be

107 concluded that the process is flexible in that range. In the feasible operation, all the constraints (heat

108 and material balance, capacity, and equipment specifications) must be satisfied.

109 This study aims at investigating a suitable process in order to optimally liquefy an associated natural

110 gas stream. To this end, two types of liquefaction processes (an SMR process and a nitrogen expander

111 process) were modelled and optimized, and then their economic performances were compared. An

112 Equation-Oriented (EO) approach was adopted to model the processes. The total lifecycle cost of the

113 plants, operating for 25 years, was considered as the objective function. This objective covers both

114 operational and capital costs and establishes a reasonable trade-off between power consumption and

115 total heat exchanger surface area. As a post-optimization study, the flexibility of the SMR and

116 nitrogen expander processes was compared using the enumeration of the feasible region. For this

117 goal, a range for the feed conditions (flowrate and methane content) was considered while fixing the

118 design parameters of the processes.

119 This section presented the research context. The rest of this paper is organized as follows. In Section 1202 , initially, the design problem is presented and the process modeling approach are discussed. Then,

121 the optimization formulation and the procedure of process flexibility analysis are discussed.

122 Afterward, in Section 3, the results of both the optimization and the flexibility analysis are presented

123 and compared for the liquefaction processes. Finally, Section 4 presents the conclusion of this 124 research.

\section{2. Problem statement and methodology}

\subsection{Process modeling}

127 This study investigated the potential of utilizing an associated natural gas stream by liquefying it and

128 producing LNG. The gas conditions and the LNG specifications are presented in Table 1. 


\begin{tabular}{lcc}
\multicolumn{1}{c}{ Parameter } & Natural Gas & LNG \\
\hline Temperature $\left({ }^{\circ} \mathrm{C}\right)$ & 35 & -158.3 \\
\hline Pressure (bar) & 40 & 1.05 \\
\hline Flowrate (kmol/h) & 2673.0 & 2673.0 \\
\hline Composition (mole \%) & & \\
Carbon dioxide & 0.47 & 0.47 \\
Methane & 85.27 & 85.27 \\
Ethane & 7.39 & 7.39 \\
Propane & 5.31 & 5.31 \\
Butanes & 1.01 & 1.01 \\
Pentanes & 0.46 & 0.46 \\
Hexanes & 0.09 & 0.09 \\
Nitrogen & 0.00 & 0.00 \\
$\mathrm{H}_{2} \mathrm{~S}$ & 0.00 & 0.00 \\
\hline Liquefaction cooling load $(\mathrm{kW})$ & 11987.5 & - \\
\hline
\end{tabular}

131 This gas is produced as a byproduct from an offshore and remote oil filed. Therefore, it is crucial to

132 select a small-scale and compact process in order to meet offshore requirements. As discussed in

133 Section 1, single-stage mixed-refrigerant (SMR) and nitrogen expander processes are two suitable

134 candidates for small-scale applications. These processes have relatively simple configuration, require

135 low capital investment, and provide quick start-up and shut-down [10,11].

136 PRICO (Poly-Refrigerated Integrated Cycle Operations) is one of the well-known SMR processes

137 which is widely used in small-scale liquefaction facilities [10,11,18,23]. Figure 1 shows the flow

138 diagram of this process.

139 In liquefaction processes, the number of compressor stages depends on the compression ratio which

140 is limited to about four for each compression stage [24]. In comparison to single-stage compressor

141 systems, two-stage systems with intermediate cooling will increase the efficiency [25,26]. In this

142 process, the natural gas stream (stream NG1) enters the MHEX where it is cooled (stream NG2).

143 Furthermore, it is expanded to a near atmospheric pressure (stream LNG) and then it is transported

144 as the LNG product. The cooling duty is provided by a refrigeration cycle using a multi-component

145 working fluid (mixed-refrigerant). Conventionally, the mixture consists of nitrogen, methane, ethane,

146 propane and butanes [27]. In this process, a constraint on the degree of superheating for stream 4 Assigned paper number: JERT-19-1723 
147 should be considered. It is a practical safety consideration to prevent the formation of liquid droplets

148 which could be detrimental in the compressor system. Moreover, it is worth mentioning that in an

149 energy effective LNG process, there will be relatively small differences between the hot and cold

150 composite curve in the MHEX, as large temperature differences lead to irreversibilities and exergy

151 destruction [28]. However, reducing the gap between the composite curves results in the requirement

152 of a large heat transfer area. Therefore, there is always a trade-off between the size of the MHEX and

153 the energy consumption of the compressor. Since LNG processes are very energy intensive, the

154 minimum internal temperature approach is usually small [27].

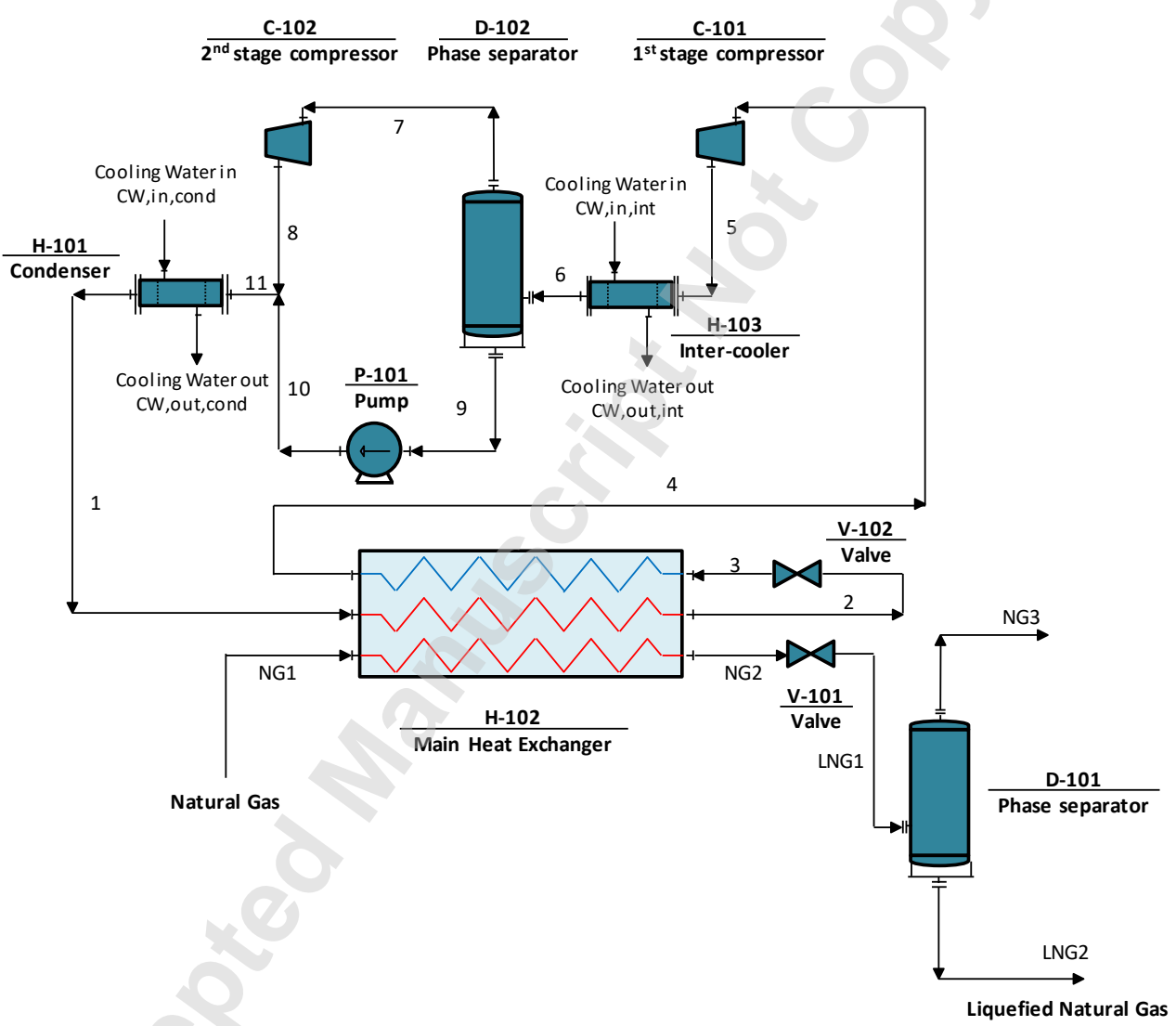

Fig. 1 PRICO process flow diagram

157 The decision variables of the PRICO process are the suction pressure (the pressure before the

158 compressor system), first stage discharge pressure, second stage discharge pressure, and the flowrates

159 of mixed-refrigerant components. Table 2 shows the lower and upper bounds for these variables

160 which were considered in this study. 
Table 2 PRICO process variable constraints

\begin{tabular}{lcc}
\multicolumn{1}{c}{ Process design variables } & Lower Limit & Upper Limit \\
\hline Suction pressure (bar) & 1.50 & 8.00 \\
\hline $1^{\text {st }}$ stage discharge pressure (bar) & 1.50 & 90.00 \\
\hline $2^{\text {nd }}$ stage discharge pressure (bar) & 1.50 & 90.00 \\
\hline Mixed-refrigerant component flowrate $(\mathrm{kmol} / \mathrm{h})$ & 0.0 & 5,000 \\
\hline Minimum internal temperature approach $(\mathrm{K})$ & 3.0 & - \\
\hline Degree of superheating $(\mathrm{K})$ & 10.0 & - \\
\hline
\end{tabular}

163 Compared to SMR processes, nitrogen expander processes require smaller heat transfer area and are

164 more compact while they consume more energy in the compressor system. A conventional nitrogen

165 expander process consists of a multi-stage compressor system, an after cooler, a main heat exchanger,

166 and an expander [29]. Figure 2 illustrates the process flow diagram of a nitrogen single-expander

167 cycle.

170 The nitrogen expander process which is shown in has totally five decision variables (suction pressure,

$1711^{\text {st }}$ stage discharge pressure, $2^{\text {nd }}$ stage discharge pressure, $3^{\text {rd }}$ stage discharge pressure, and nitrogen

172 flowrate). Table 3 presents the lower and upper bounds for these variables which were considered in

173 this study.

Assigned paper number: JERT-19-1723

Corresponding author's last name: Rashtchian 
Table 3 Nitrogen expander process variable constraints

\begin{tabular}{lcc}
\hline \multicolumn{1}{c}{ Process design variables } & Lower Limit & Upper Limit \\
\hline Suction pressure (bar) & 1.50 & 10.0 \\
\hline $1^{\text {st }}$ stage discharge pressure (bar) & 1.50 & 90.0 \\
\hline $2^{\text {nd }}$ stage discharge pressure (bar) & 1.50 & 90.0 \\
\hline $3^{\text {rd }}$ stage discharge pressure (bar) & 1.50 & 90.0 \\
\hline Nitrogen flowrate $(\mathrm{kmol} / \mathrm{h})$ & 0.0 & 20,000 \\
\hline Minimum internal temperature approach $(\mathrm{K})$ & 3.0 & - \\
\hline Degree of superheating $(\mathrm{K})$ & 10.0 & - \\
\hline
\end{tabular}

176 In this study, an equation-oriented (EO) approach was adopted to model the PRICO and expander

177 processes [30]. EO approach enables simultaneous optimization and convergence of the whole

178 flowsheet, using an appropriate optimization algorithm. Rigorous thermodynamic calculations were

179 conducted using Peng-Robinson equation of states. For two-phase calculations, the formulation

180 proposed by Kamath et al. [31] was implemented. For the main heat exchanger, a detailed modeling

181 was conducted using energy balance equations with internal temperature feasibility constraints. The

182 temperature feasibility condition implies that the temperature difference between the hot and cold

183 composite curves at any internal point must be greater than the minimum internal temperature

184 approach value [32].

185 In the following section the formulation of the objective function is explained.

$186 \quad 2.2$. Objective function

187 In order to design a liquefaction process, there is always a trade-off between power consumption and

188 heat transfer area. In order to balance this situation, one of the most reliable objective functions is the

189 plant total lifecycle cost which includes both operational and capital costs [18]. Complete liquefaction

190 of the feed gas stream was supposed in this study, therefore, the LNG sale profit was fixed and was

191 not considered in the objective function. The plants were considered to operate for a period of twenty-

192 five years and 330 days per year. The electricity price was supposed to be $6.95 \phi / k W h$ [18]. The rise

193 in the electricity price during this period was considered to be $3 \%$ per annum [18]. 
194 For capital cost, only the purchase costs of compressors, turbine, and MHEX were considered. The

195 costs of other equipment are negligible, compared to these elements [18]. The capital cost is finally

196 multiplied by three in order to consider the installation, piping, set up and other supplementary prices

$197[18]$.

198 The purchase cost of a centrifugal compressor was calculated using the following equation [33]:

$$
C_{B}=\exp \left\{9.1553+0.63\left[\ln \left(P_{C}\right)\right]\right\}
$$

199 Here $C_{B}$ and $P_{c}$ are the FOB (free on board) price (US dollars in 2013) and power consumption of a

200 compressor (horsepower, $h p$ ), respectively.

201 For the estimation of the purchase cost of an expander, the following correlation was used [33]:

$$
C_{B}=600 P_{E}^{0.81}
$$

202 In this equation $C_{B}$ is the FOB price of an expander in US dollars (price in 2013) and $P_{E}$ is the 203 generated power in horsepower $(h p)$.

204 The main heat exchanger price was calculated based on $425 U S \$ / m^{2}$ in 2011 and considering an 205 overall heat transfer coefficient, U, of $700 \mathrm{~kJ} / \mathrm{m}^{2} . h . K[18]$ :

$$
C_{B}=425 A
$$

206 In this formula $C_{B}$ is the FOB price of the MHEX in US dollars (price in 2011) and $A$ is the heat 207 transfer area of the MHEX (in $m^{2}$ ).

208 The objective function was calculated based on the prices in 2018, therefore chemical engineering's 209 plant cost index $(\mathrm{CEPCI})$ was considered to adjust the prices $\left(\mathrm{CEPCI}_{2011}=585.7, \mathrm{CEPCI}_{2013}=567.3\right.$, 210 and $\left.\mathrm{CEPCI}_{2018}=603.1\right)$ [34]. 


\section{$211 \quad$ 2.3. Flexibility analysis}

212 In this study, flexibility analysis (using feasible region enumeration) was used to identify the extent

213 to which the uncertainty or changes in the feed condition are tolerated by the optimal designs. In other

214 words, after the process optimization using the baseline feed condition (Table 1), both processes were

215 optimized considering a range of feed overall flowrate and methane content (as the dominant

216 component of the natural gas).

217 For this analysis, two more constraints were added to the optimization problem. First, the heat transfer

218 area (UA) was supposed to be less or equal than the optimized value (the value obtained for the

219 baseline feed conditions). This constraint limited the available heat transfer area to the optimized

220 value. Second, the refrigerant flowrate inside the liquefaction cycle was limited to vary in a range of

$22190 \%$ to $110 \%$ of the optimized flowrate (the value obtained for the baseline feed conditions). This

222 ensures a reasonable flowrate with respect to the optimized capacity of the cycles.

223 In order to form a feasibility-check region, a range between $-10 \%$ and $+10 \%$ of the baseline feed

224 flowrate was supposed for the natural gas flowrate, and for the methane content a range between 50\%

225 to $95 \%$ was considered. In order to generate feed sample points (totally 5000 samples) in such a way

226 that uniformly covers the above-mentioned range, Latin Hypercube Sampling (LHS) was used

227 [35,36]. LSH is an efficient method for generating random samples of uncertain parameters in a multi-

228 dimensional design space [36]. The distribution of the samples is shown in Fig. 3. The star symbol in 229 the figure shows the baseline feed condition. 


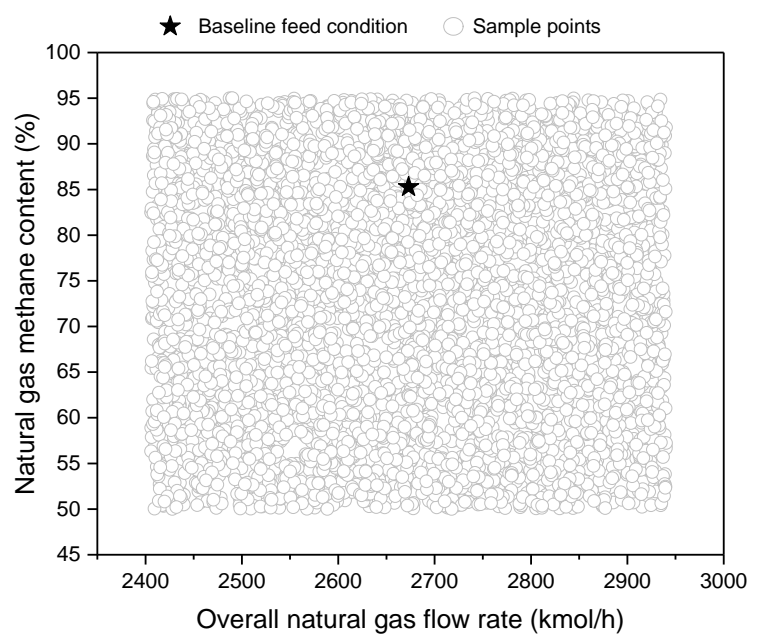

Fig. 3 The sample region for the flexibility analysis

232 As the methane content of the natural gas increases, the temperature of the natural gas which leaves

233 the MHEX (stream NG2 in Fig. 1 and Fig. 2) decreases. Therefore, the refrigerant must provide such

234 a low temperature. On the other hand, as the methane content decreases the feed becomes heavier.

235 Hence, the cooling load that must be absorbed by the cycle increases. By increasing the feed flowrate,

236 the cooling load also increases. Figure 4 shows the gas leaving temperature as well as the required 237 cooling load for the feed samples generated in this section. As this figure shows, the bottom-right part 238 of the region has the highest cooling load.

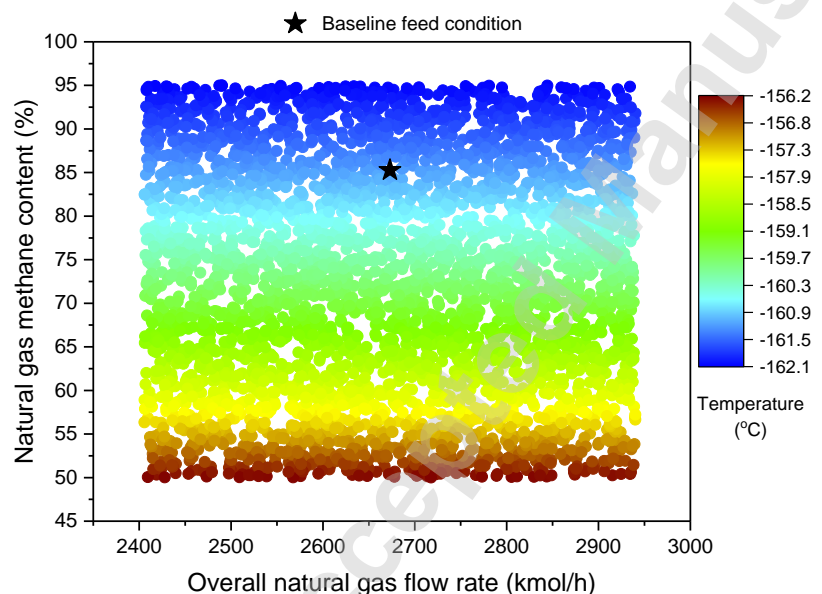

(a)

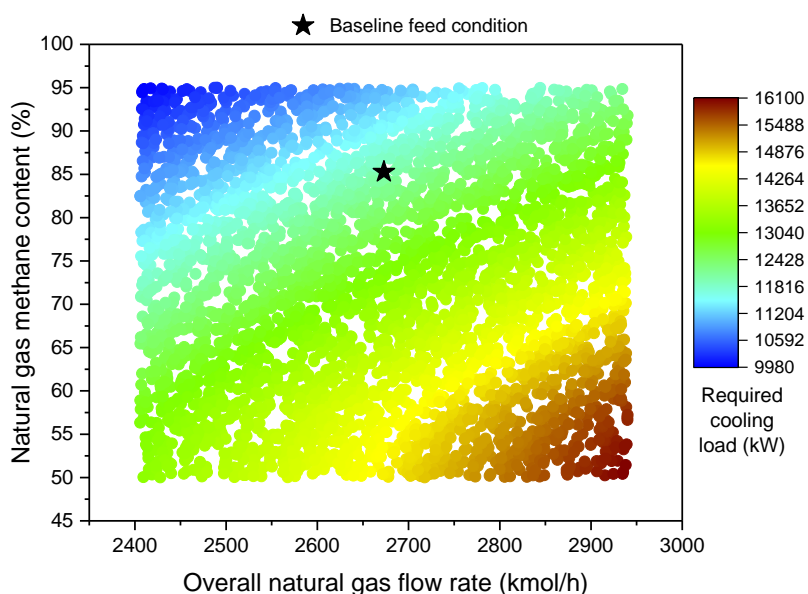

(b)

Fig. 4 (a) The temperature of the natural gas after the MHEX, and (b) The required cooling load for each feed sample 
242 Considering the overall region shown in Fig. 3, the process which feasibly operates in more points

243 (feed samples) is considered to be more flexible. The next section presents the optimization results

244 as well as the results of the flexibility analysis.

\section{3. Results and discussion}

246 The PRICO and nitrogen expander processes were modeled in GAMS software (version 24.7.4) [37].

247 These models were formulated as NLP (nonlinear programming) problems and solved using 248 CONOPT (CONtinuous OPTimization) solver [38] in GAMS. In order to well initialize the 249 optimization process, the processes were first simulated in Aspen HYSYS (version 8.8) software and 250 the initial value of the variables was extracted from the simulation case.

\subsection{Optimization results}

252 Considering the lifecycle costs as the objective function, the PRICO and nitrogen expander processes

253 were optimized. Table 4 and Table 5 show the optimization results for the PRICO process and 254 nitrogen expander process, respectively.

Table 4 The optimal solution of the PRICO process

\begin{tabular}{lc}
\hline \multicolumn{1}{c}{ Variable } & Optimal value \\
\hline Suction pressure (bar) & 1.52 \\
\hline $1^{\text {st }}$ stage discharge pressure (bar) & 6.08 \\
\hline $2^{\text {nd }}$ stage discharge pressure (bar) & 24.30 \\
\hline Mixed-refrigerant flowrate (kmol/h) & 5930.1 \\
\hline Mixed-refrigerant composition $(\%)$ & \\
nitrogen & 6.46 \\
methane & 21.42 \\
ethane & 35.34 \\
propane & 0.00 \\
i-butane & 0.00 \\
n-butane & 36.78 \\
\hline Power consumption $(\mathrm{MW})$ & 14.91 \\
\hline UA (kJ/K.h) & $3.04 \times 10^{7}$ \\
\hline Capital cost $(\$)$ & $77 \times 10^{6}$ \\
\hline Operating cost $(\$), 25$ years operation & $298 \times 10^{6}$ \\
\hline Plant total cost $(\$), 25$ years operation & $375 \times 10^{6}$ \\
\hline
\end{tabular}


Table 5 The optimal solution of the nitrogen expander process

\begin{tabular}{lc}
\multicolumn{1}{c}{ Variable } & Optimal value \\
\hline Suction pressure (bar) & 1.82 \\
\hline $1^{\text {st }}$ stage discharge pressure (bar) & 6.96 \\
\hline $2^{\text {nd }}$ stage discharge pressure (bar) & 25.44 \\
\hline $3^{\text {rd }}$ stage discharge pressure (bar) & 90.00 \\
\hline Nitrogen flowrate $(\mathrm{kmol} / \mathrm{h})$ & 10646.1 \\
\hline Power consumption $(\mathrm{MW})$ & 34.06 \\
\hline UA $(\mathrm{kJ} / \mathrm{K} . \mathrm{h})$ & $3.73 \times 10^{6}$ \\
\hline Capital cost $(\$)$ & $58 \times 10^{6}$ \\
\hline Operating cost $(\$), 25$ years operation & $680 \times 10^{6}$ \\
\hline Plant total cost $(\$), 25$ years operation & $738 \times 10^{6}$ \\
\hline
\end{tabular}

262 As Table 4 and Table 5 show, the PRICO process is economically more attractive than the nitrogen

263 expander process for the liquefaction of the associated natural gas stream. Although nitrogen 264 expander process has a significantly smaller UA, but it requires more shaft work (128\% higher) than

265 that of the PRICO process.

\subsection{Flexibility analysis}

267 As it was discussed in Section 2.3, considering a range between $2406 \mathrm{kmol} / \mathrm{h}(-10 \%$ of the baseline 268 feed flowrate) to $2940 \mathrm{kmol} / \mathrm{h}(+10 \%$ of the baseline feed flowrate) for the natural gas flowrate and a 269 range between $50 \%$ to $95 \%$ for the natural gas methane content, 5000 feed samples were generated 270 using LHS method (as shown in Fig. 3). Both PRICO and nitrogen expander processes were 271 optimized for each sample. In order to fix the process designs, two more constraints were added to 272 the process models with respect to the optimal design parameters in Table 4 and Table 5; one

273 constraint was considered to limit the process flowrate (a representative measure of the cycle 274 capacity) and another to provide an upper limit on the available heat transfer area. These constraints 275 are as follows:

276 For the PRICO process:

$$
\begin{aligned}
& {\left[0.9 \times 5930.1 \frac{\mathrm{kmol}}{\mathrm{h}}=5337.1 \frac{\mathrm{kmol}}{\mathrm{h}}\right] \leq \text { MR Flowrate } \leq\left[1.1 \times 5930.1 \frac{\mathrm{kmol}}{\mathrm{h}}=6523.1 \frac{\mathrm{kmol}}{\mathrm{h}}\right]} \\
& U A \leq 3.04 \times 10^{7} \frac{\mathrm{kJ}}{\mathrm{K} . \mathrm{h}}
\end{aligned}
$$

277 For the nitrogen expander process: 


$$
\begin{aligned}
& {\left[0.9 \times 10646.1 \frac{\mathrm{kmol}}{\mathrm{h}}=9581.5 \frac{\mathrm{kmol}}{\mathrm{h}}\right] \leq N_{2} \text { flow rate } \leq\left[1.1 \times 10646.1 \frac{\mathrm{kmol}}{\mathrm{h}}=11710.7 \frac{\mathrm{kmol}}{\mathrm{h}}\right]} \\
& U A \leq 3.73 \times 10^{6} \frac{\mathrm{kJ}}{\mathrm{K} . \mathrm{h}}
\end{aligned}
$$

278 Figure 5 presents the results (feasible samples) for the PRICO process. As this figure shows the 279 PRICO process is feasible for the entire region.

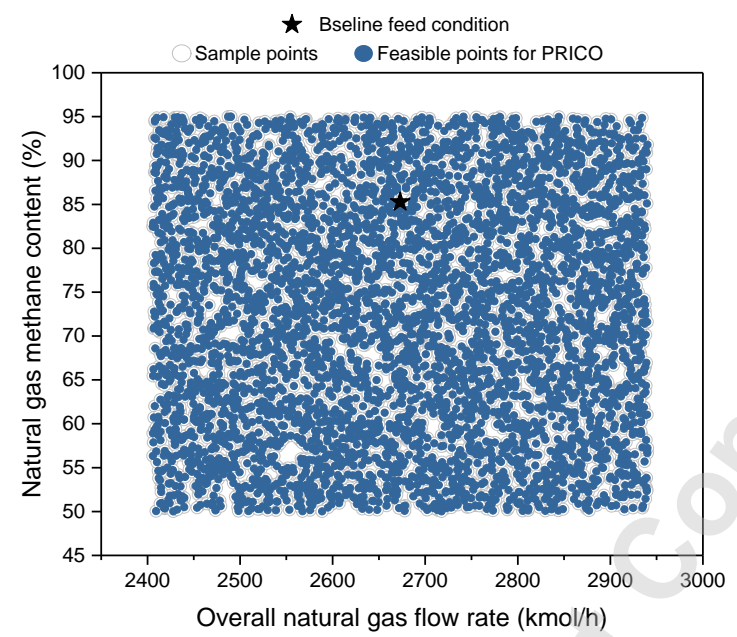

Fig. 5 the flexible region for the optimal PRICO process

282 The contour plot of the refrigerant flowrate and power consumption for the feasible points of the

283 PRICO process are shown in Fig. 6.

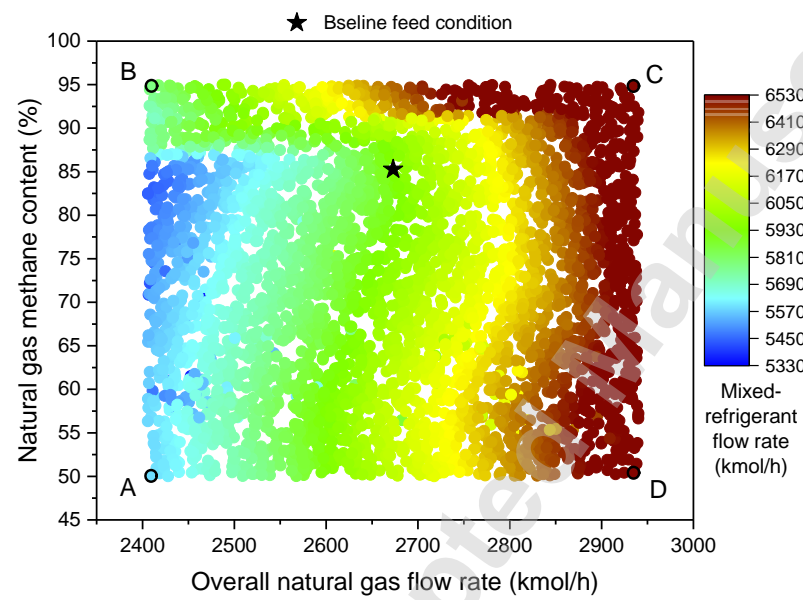

(a)

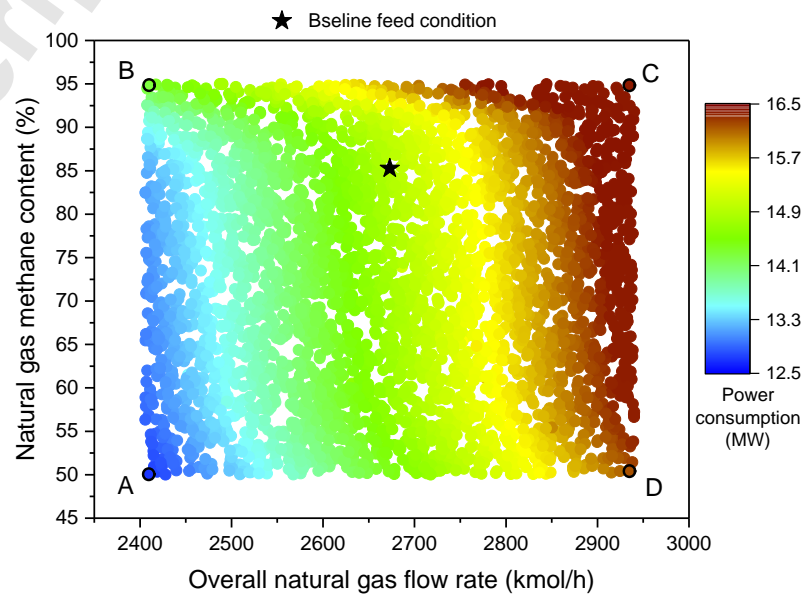

(b)

285 As Fig. 6 (a) shows the upper limit of the mixed-refrigerant flowrate is touched for the feed samples 286 with high natural gas flowrate and high methane content. Also the figure shows that such feed samples 287 require more power consumption (Fig. 6 (b)). 
288 Table 6 presents the feed conditions as well as the optimal design parameters for the points A, B, C,

289 and D which are shown in Fig. 6.

Table 6 Feed condition and optimal design for the points shown in Fig. 6

\begin{tabular}{|c|c|c|c|c|c|}
\hline Parameter & & Point A & Point B & $\overline{\text { Point } \mathrm{C}}$ & $\overline{\text { Point D }}$ \\
\hline \multirow{12}{*}{ Feed conditions } & Temperature $\left({ }^{\circ} \mathrm{C}\right)$ & 35 & 35 & 35 & 35 \\
\hline & Pressure (bar) & 40 & 40 & 40 & 40 \\
\hline & Flowrate $(\mathrm{kmol} / \mathrm{h})$ & 2409.4 & 2410.2 & 2934.4 & 2934.7 \\
\hline & Composition (\%) & & & & \\
\hline & Carbon dioxide & 1.59 & 0.16 & 0.16 & 1.58 \\
\hline & Methane & 50.05 & 94.84 & 94.85 & 50.41 \\
\hline & Ethane & 25.07 & 2.59 & 2.59 & 24.89 \\
\hline & Propane & 18.00 & 1.86 & 1.86 & 17.87 \\
\hline & Butanes & 3.40 & 0.35 & 0.35 & 3.37 \\
\hline & Pentanes & 1.58 & 0.16 & 0.16 & 1.57 \\
\hline & Hexanes & 0.31 & 0.03 & 0.03 & 0.31 \\
\hline & Cooling load $(\mathrm{kW})$ & 13222.1 & 9993.9 & 12166.3 & 16094.8 \\
\hline \multirow{11}{*}{$\begin{array}{l}\text { Optimal process } \\
\text { variables }\end{array}$} & Suction pressure (bar) & 1.60 & 1.50 & 1.50 & 1.50 \\
\hline & Intermediate pressure (bar) & 5.07 & 5.76 & 6.00 & 5.84 \\
\hline & Discharge pressure (bar) & 20.30 & 23.03 & 24.0 & 23.34 \\
\hline & Mixed-refrigerant flowrate $(\mathrm{kmol} / \mathrm{h})$ & 5590.6 & 5786.0 & 6523.1 & 6523.1 \\
\hline & Mixed-refrigerant composition (\%) & & 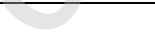 & & \\
\hline & nitrogen & 5.37 & 6.47 & 6.56 & 5.28 \\
\hline & methane & 22.58 & 21.39 & 20.88 & 23.28 \\
\hline & ethane & 26.83 & 38.64 & 41.41 & 26.74 \\
\hline & n-butane & 45.21 & 33.50 & 31.15 & 44.71 \\
\hline & Power consumption (MW) & 12.71 & 14.30 & 16.40 & 16.17 \\
\hline & $\mathrm{UA}(\mathrm{kJ} / \mathrm{K} . \mathrm{h})$ & $3.04 \times 10^{7}$ & $2.37 \times 10^{7}$ & $2.84 \times 10^{7}$ & $3.04 \times 10^{7}$ \\
\hline
\end{tabular}

291 As Table 6 shows, when the methane content decreases (heavier feed samples, such as points A and

292 D), the mixed-refrigerant becomes heavier by increasing the flowrate of the heaviest component (n-

293 butane) in order to provide the cooling load. This fact is also shown in Fig. 7.

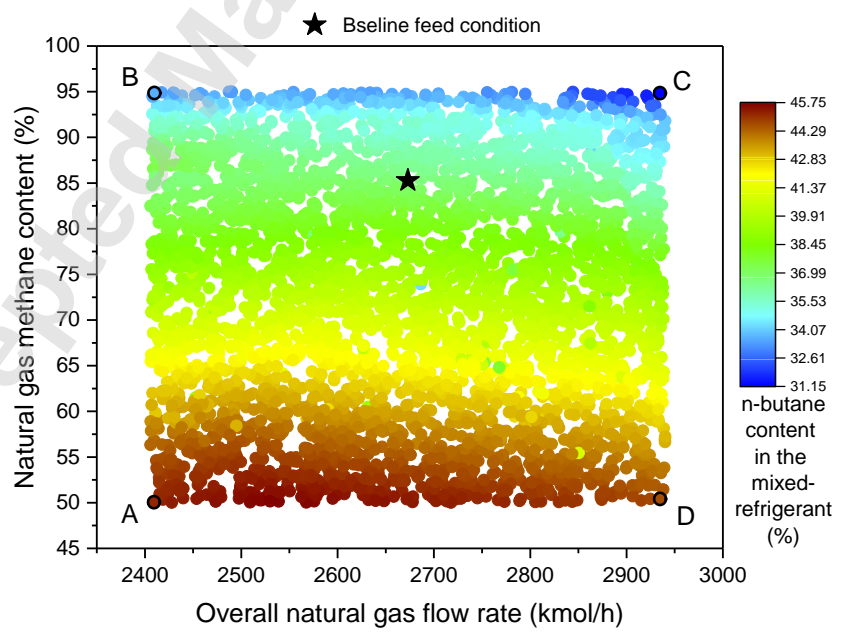

Fig. 7 n-butane content in the mixed-refrigetant for the feasible region of the PRICO process 
297 Figure 8 present the feasible region for the nitrogen expander processes. As this figure shows the

298 nitrogen expander process is not feasible for the bottom-right part of the region. It means that the 299 optimal design which obtained for the baseline feed condition, cannot operate for the feed samples

300 with very high cooling load. This is due to the fact that for such feed samples, the process requires

301 higher refrigerant (nitrogen) flow rate. However the refrigerant flowrate is limited by a constraint

302 (equation 6). In the PRICO process this issue is managed by making the mixed-refrigerant heavier

303 (i.e. increasing n-butane content). But this is not possible in the nitrogen expander process; because

304 the refrigerant in this process is pure nitrogen. Figure 9 shows the nitrogen flowrate as well as the 305 power consumption for the feasible region of the nitrogen expander process. As Fig. 9 shows, by 306 increasing the required cooling load of the feed (low methane content and high flowrate) the power 307 consumption of the process increases. It happens because the refrigerant flowrate is increased for 308 such conditions.

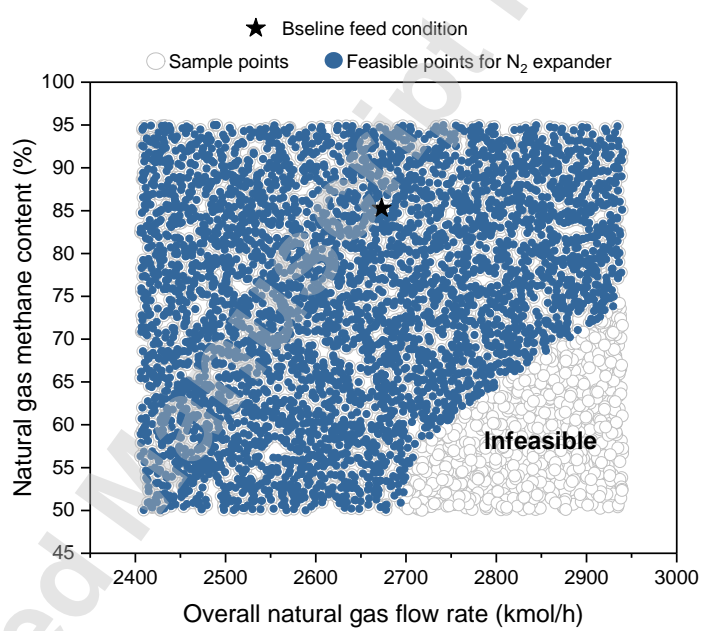

Fig. 8 the flexible region for the optimal nitrogen expander process 


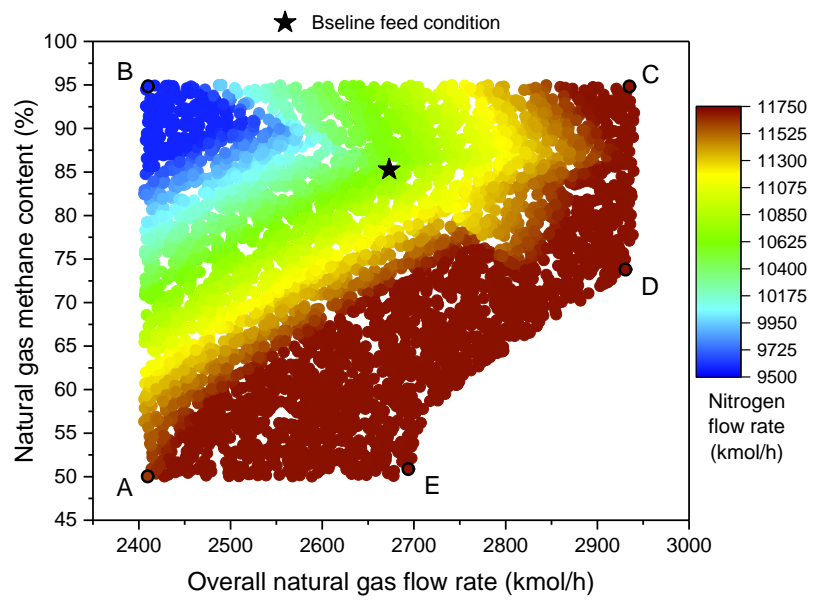

(a)

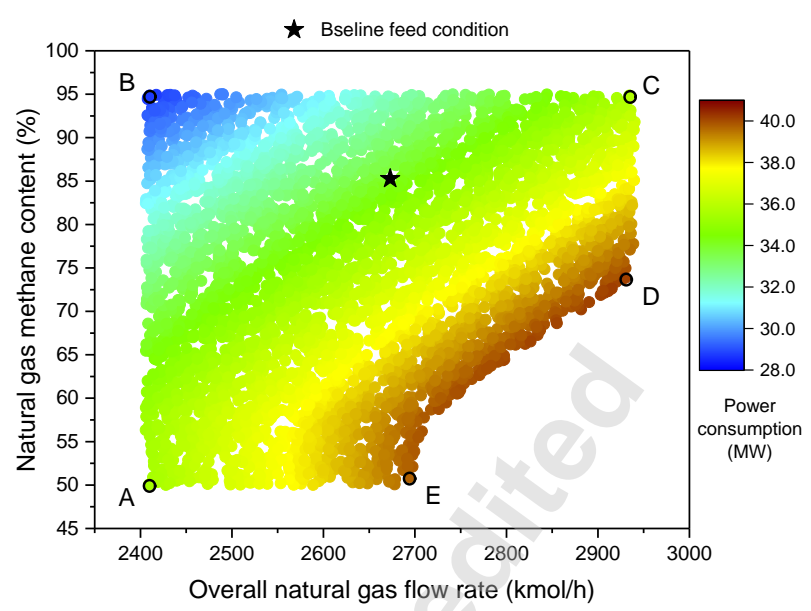

(b)

320 The feed conditions at points A, B, C, D, and E (shown in Fig. 9) as well as the optimal parameters

321 of the nitrogen expander process for these points are presented in Table 7. As this table shows, the 322 nitrogen flowrate limit is touched for the points C, D, and E, because these points have higher cooling 323 load than the others.

324 The results presented in this section showed that the PRICO process is economically more attractive

325 in order to liquefy the associated natural gas stream; its power consumption (which is the dominant

326 factor in the lifecycle costs of a liquefaction process) is lower than the nitrogen expander process.

327 The nitrogen expander process requires smaller heat transfer area and consequently it has lower 328 capital investment in comparison to the PRICO process.

329 The results of the flexibility analysis showed that the nitrogen expander process cannot feasibly 330 operate at high feed flowrate and low methane content (higher cooling load) while the PRICO process 331 is more flexible and operates in the entire feasibility-check region. 
Table 7 Feed condition and optimal design for the points shown in Fig. 9

\begin{tabular}{|c|c|c|c|c|c|c|}
\hline & Parameter & Point A & Point B & Point $\mathrm{C}$ & Point D & Point E \\
\hline \multirow{12}{*}{$\begin{array}{l}\text { Feed } \\
\text { conditions }\end{array}$} & Temperature $\left({ }^{\circ} \mathrm{C}\right)$ & 35 & 35 & 35 & 35 & 35 \\
\hline & Pressure (bar) & 40 & 40 & 40 & 40 & 40 \\
\hline & Flowrate $(\mathrm{kmol} / \mathrm{h})$ & 2409.4 & 2410.2 & 2934.4 & 2929.6 & 2694.2 \\
\hline & Composition (\%) & & & & & \\
\hline & Carbon dioxide & 1.59 & 0.16 & 0.16 & 0.83 & 1.56 \\
\hline & Methane & 50.05 & 94.84 & 94.85 & 73.83 & 50.90 \\
\hline & Ethane & 25.07 & 2.59 & 2.59 & 13.14 & 24.65 \\
\hline & Propane & 18.00 & 1.86 & 1.86 & 9.43 & 17.69 \\
\hline & Butanes & 3.40 & 0.35 & 0.35 & 1.78 & 3.34 \\
\hline & Pentanes & 1.58 & 0.16 & 0.16 & 0.83 & 1.56 \\
\hline & Hexanes & 0.31 & 0.03 & 0.03 & 0.16 & 0.31 \\
\hline & Cooling Load (kW) & 13222.1 & 9993.9 & 12166.3 & 14280.8 & 14763.0 \\
\hline \multirow{7}{*}{$\begin{array}{l}\text { Optimal } \\
\text { process } \\
\text { variables }\end{array}$} & Suction pressure (bar) & 2.03 & 2.27 & 2.11 & 1.51 & 1.51 \\
\hline & 1st stage discharge pressure (bar) & 7.48 & 8.06 & 7.89 & 5.64 & 5.65 \\
\hline & 2nd stage discharge pressure (bar) & 26.37 & 27.37 & 27.08 & 22.57 & 22.60 \\
\hline & 3rd stage discharge pressure (bar) & 90.00 & 90.00 & 90.00 & 90.00 & 90.00 \\
\hline & Nitrogen flowrate $(\mathrm{kmol} / \mathrm{h})$ & 11624.1 & 9581.5 & 11710.7 & 11710.7 & 11710.7 \\
\hline & Power consumption (MW) & 35.43 & 28.73 & 35.72 & 40.17 & 39.74 \\
\hline & UA (kJ/K.h) & $2.92 \times 10^{6}$ & $3.62 \times 10^{6}$ & $3.73 \times 10^{6}$ & $3.73 \times 10^{6}$ & $3.09 \times 10^{6}$ \\
\hline
\end{tabular}

\section{4. Conclusion}

339 Associated natural gas is one of the natural gas resources which is produced as a byproduct in oil

340 fields. Such gas resources are usually flared or vented, contributing a major part in global greenhouse

341 gas emissions. This research focused on the optimization of liquefaction processes in order to liquefy

342 an associated natural gas stream. To this end, two small-scale liquefaction processes (PRICO process

343 and nitrogen expander process) were modeled and optimized using an equation-oriented approach.

344 The objective function was the plant lifecycle costs in which both capital and operation costs were

345 included for a period of twenty-five years. This objective function was selected because it can

346 establish a reasonable trade-off between shaft work and total heat exchanger surface area of the

347 liquefaction processes. The results showed that the PRICO process is economically more attractive

348 (49\% lower lifecycle cost compared to the nitrogen expander process). Although it requires a

349 considerably larger heat transfer area and consequently higher capital cost, it consumes $56 \%$ lower

350 shaft work which has the dominant effects on the lifecycle cost. 
351 Besides the economic performance, the flexibility of liquefaction processes is an important issue

352 which is not usually considered in the optimization studies. This is an important issue specially when

353 the feed is an associated gas stream. In such cases, the gas flow is normally unsteady. Moreover, the

354 associated gas in one oil field may exhaust in a few years and the liquefaction plant should be moved

355 to another oil field with different gas specifications. The results of the flexibility analysis provide an

356 in-depth insight regarding the behavior of the processes in case of gas flow fluctuations which has

357 not been well studied before. In this research, the flexibility of the aforementioned liquefaction

358 processes was also studied. For this purpose, it was supposed that the feed gas flowrate can vary in a

359 range of $\pm 10 \%$ of the baseline value and the methane content of the feed gas varies between $50 \%$ to

360 95\%. Using Latin Hypercube Sampling (LHS), five-thousand feed samples were generated which

361 formed a feasibility-check region. The processes were optimized again for each feed sample

362 considering two more constraints which made the designs to be fixed (refrigerant flowrate and overall

363 heat transfer coefficient) and the feasible region of each design was identified. The results showed

364 that with respect to the design constraints, the PRICO process is more flexible and operates in the

365 entire feed condition region. However, the nitrogen process could not feasibly operate for the feed

366 samples with high flowrate and low methane content. 


\title{
375 5. Nomenclature
}

\author{
$\underline{\text { Abbreviations }}$ \\ ANG Associated Natural Gas \\ CEPCI Chemical Engineering's Plant Cost Index \\ EO Equation-Oriented \\ FOB Free On Board \\ LHS Latin Hypercube Sampling \\ LNG Liquefied Natural Gas \\ MHEX Main Heat Exchanger \\ MR Mixed-Refrigerant \\ PRICO Poly-Refrigerated Integrated Cycle Operations \\ SM Sequential Modular \\ SMR Single-stage Mixed-Refrigerant

\section{Symbol} \\ A Heat transfer area of the $\operatorname{MHEX}\left(\mathrm{m}^{2}\right)$ \\ $\mathrm{C}_{\mathrm{B}} \quad$ Free on board price (US dollars) \\ $\mathrm{P}_{\mathrm{c}} \quad$ Power consumption of a compressor (horsepower, hp) \\ $\mathrm{P}_{\mathrm{E}} \quad$ Expander generated power (horsepower, hp) \\ $\mathrm{U} \quad$ Overall heat transfer coefficient $\left(\mathrm{kJ} / \mathrm{m}^{2} . \mathrm{h} . \mathrm{K}\right)$ \\ UA The product of overall heat transfer coefficient and heat transfer area $(\mathrm{kJ} / \mathrm{h} . \mathrm{K})$
}




\section{References}

380 [1] Tabkhi, F., Pibouleau, L., Azzaro-Pantel, C., and Domenech, S., 2009, "Total Cost

Minimization of a High-Pressure Natural Gas Network," J. Energy Resour. Technol., 131(4).

[2] Qyyum, M. A., Qadeer, K., and Lee, M., 2018, “Comprehensive Review of the Design Optimization of Natural Gas Liquefaction Processes: Current Status and Perspectives," Ind. Eng. Chem. Res., 57(17), pp. 5819-5844.

[3] Beltrán-Jiménez, K., Chávez-Rodríguez, M. F., and Szklo, A., 2018, “Associated Natural Gas Flare in the Integrated Market of the Southern Cone,” Energy Strateg. Rev., 22(May), pp. 337347.

[4] Xu, X., Liu, J., Jiang, C., and Cao, L., 2013, "The Correlation between Mixed Refrigerant Composition and Ambient Conditions in the PRICO LNG Process," Appl. Energy, 102, pp. 1127-1136.

[5] Moein, P., Sarmad, M., Ebrahimi, H., Zare, M., Pakseresht, S., and Vakili, S. Z., 2015, “APCILNG Single Mixed Refrigerant Process for Natural Gas Liquefaction Cycle: Analysis and Optimization,” J. Nat. Gas Sci. Eng., 26, pp. 470-479.

[6] Austb $\varnothing$, B., and Gundersen, T., 2015, "Optimization of a Single Expander LNG Process," Energy Procedia, 64(C), pp. 63-72.

[7] Lin, W., Huang, M., He, H., and Gu, A., 2009, “A Transcritical CO2 Rankine Cycle With LNG Cold Energy Utilization and Liquefaction of CO2 in Gas Turbine Exhaust,” J. Energy Resour. Technol., 131(4).

[8] Widiyanto, A., Kato, S., and Maruyama, N., 2002, "A LCA/LCC Optimized Selection of Power Plant System With Additional Facilities Options,” J. Energy Resour. Technol., 124(4), pp. 290-299.

[9] Gurgenci, H., and Aminossadati, S. M., 2009, "Investigating the Use of Methane as Diesel Fuel in Off-Road Haul Road Truck Operations," J. Energy Resour. Technol., 131(3).

[10] He, T., Karimi, I. A., and Ju, Y., 2018, "Review on the Design and Optimization of Natural Gas Liquefaction Processes for Onshore and Offshore Applications," Chem. Eng. Res. Des., 132, pp. 89-114.

[11] Castillo, L., and Dorao, C. A., 2010, "Influence of the Plot Area in an Economical Analysis for Selecting Small Scale LNG Technologies for Remote Gas Production," J. Nat. Gas Sci. Eng., 2(6), pp. 302-309.

[12] Austbø, B., Løvseth, S. W., and Gundersen, T., 2014, "Annotated Bibliography-Use of Optimization in LNG Process Design and Operation,” Comput. Chem. Eng., 71, pp. 391-414.

[13] Yin, Q. S., Li, H. Y., Fan, Q. H., and Jia, L. X., 2008, "Economic Analysis of MixedRefrigerant Cycle and Nitrogen Expander Cycle in Small Scale Natural Gas Liquefier," AIP Conf. Proc., 985(2008), pp. 1159-1165.

[14] Mokarizadeh Haghighi Shirazi, M., and Mowla, D., 2010, "Energy Optimization for Liquefaction Process of Natural Gas in Peak Shaving Plant," Energy, 35(7), pp. 2878-2885.

[15] He, T., and Ju, Y., 2014, "A Novel Process for Small-Scale Pipeline Natural Gas Liquefaction," Appl. Energy, 115, pp. 17-24.

[16] He, T., and Ju, Y., 2014, "A Novel Conceptual Design of Parallel Nitrogen Expansion Liquefaction Process for Small-Scale LNG (Liquefied Natural Gas) Plant in Skid-Mount Packages," Energy, 75, pp. 349-359.

[17] Yuan, Z., Cui, M., Xie, Y., and Li, C., 2014, "Design and Analysis of a Small-Scale Natural Gas Liquefaction Process Adopting Single Nitrogen Expansion with Carbon Dioxide PreCooling," Appl. Therm. Eng., 64(1-2), pp. 139-146.

[18] Aslambakhsh, A. H., Moosavian, M. A., Amidpour, M., Hosseini, M., and AmirAfshar, S., 2018, "Global Cost Optimization of a Mini-Scale Liquefied Natural Gas Plant," Energy, 148, pp. 1191-1200. 
428

429

430

431

432

433

434

435

436

437

438

439

440

441

442

443

444

445

446

447

448

449

450

451

452

453

454

455

456

457

458

459

460

461

462

463

464

465

466

467

468

469

470

471

472

473

474

475

476

[19] Swaney, R. E., and Grossmann, I. E., 1985, "An Index for Operational Flexibility in Chemical Process Design,” AlChE J., 31(4), pp. 621-630.

[20] Swaney, R. E., and Grossmann, I. E., 1985, "An Index for Operational Flexibility in Chemical Process Design," 31(4), pp. 631-641.

[21] Halemane, K. P., and Grossmann, I. E., 1983, "Optimal Process Design under Uncertainty," AIChE J., 29(3), pp. 425-433.

[22] Rogers, A., and Ierapetritou, M., 2015, "Feasibility and Flexibility Analysis of Black-Box Processes Part 2: Surrogate-Based Flexibility Analysis," Chem. Eng. Sci., 137, pp. 10051013.

[23] Austb $\varnothing$, B., Løvseth, S. W., and Gundersen, T., 2014, "Annotated Bibliography-Use of Optimization in LNG Process Design and Operation,” Comput. Chem. Eng., 71, pp. 391-414.

[24] Stanley, W., 1990, Chemical Process Equipment-Selection and Design, Washington.

[25] Skaugen, G., Walnum, H. T., Hammer, M., Wahl, P. E., Wilhelmsen, O., and Kolsaker, K., 2013, "Design and Optimization of Heat Exchangers in Processes Used for Liquefaction of Natural Gas," Int. Conf. Appl. Energy, (August 2015), pp. 1-9.

[26] Skaugen, G., Hammer, M., Wahl, P. E., and Wilhelmsen, T., 2015, "Constrained Non-Linear Optimisation of a Process for Liquefaction of Natural Gas Including a Geometrical and Thermo-Hydraulic Model of a Compact Heat Exchanger," Comput. Chem. Eng., 73, pp. 102115.

[27] Watson, H. A. J., Vikse, M., Gundersen, T., and Barton, P. I., 2018, “Optimization of Single Mixed-Refrigerant Natural Gas Liquefaction Processes Described by Nondifferentiable Models," Energy, 150, pp. 860-876.

[28] Aspelund, A., Gundersen, T., Myklebust, J., Nowak, M. P., and Tomasgard, A., 2010, “An Optimization-Simulation Model for a Simple LNG Process," Comput. Chem. Eng., 34(10), pp. 1606-1617.

[29] Lin, W., Gao, T., Gu, A., and Gu, M., 2010, “CBM Nitrogen Expansion Liquefaction Processes Using Residue Pressure of Nitrogen From Adsorption Separation,” J. Energy Resour. Technol., 132(3).

[30] Dowling, A. W., and Biegler, L. T., 2015, “A Framework for Efficient Large Scale EquationOriented Flowsheet Optimization,” Comput. Chem. Eng., 72, pp. 3-20.

[31] Kamath, R. S., Biegler, L. T., and Grossmann, I. E., 2010, "An Equation-Oriented Approach for Handling Thermodynamics Based on Cubic Equation of State in Process Optimization," Comput. Chem. Eng., 34(12), pp. 2085-2096.

[32] Tak, K., Kwon, H., Park, J., Cho, J. H., and Moon, I., 2018, “A Multistream Heat Exchanger Model with Enthalpy Feasibility,” Comput. Chem. Eng., 115, pp. 81-88.

[33] Seider, W. D., Lewin, D. R., Seader, J. D., Widagdo, S., Gani, R., and Ng, K. M., 2017, Product and Process Design Principles: Synthesis, Analysis, and Evaluation, Wiley, New York.

[34] Chemical Engineering, 2019, "Chemical Engineering Essentials for the CPI Professional" [Online]. Available: https://www.chemengonline.com/. [Accessed: 04-Mar-2019].

[35] Chen, L., and MacDonald, E., 2017, "Wind Farm Layout Sensitivity Analysis and Probabilistic Model of Landowner Decisions," J. Energy Resour. Technol., 139(3).

[36] Beyhaghi, S., and Amano, R. S., 2019, "Multivariable Analysis of Aerodynamic Forces on Slotted Airfoils for Wind Turbine Blades,” J. Energy Resour. Technol., 141(5).

[37] Bussieck, M. R., and Meeraus, A., 2004, "General Algebraic Modeling System (GAMS)," Modeling Languages in Mathematical Optimization, Springer, pp. 137-157.

[38] Drud, A. S., 1994, "CONOPT—a Large-Scale GRG Code," ORSA J. Comput., 6(2), pp. 207216. 


\section{List of table captions}

478 Table 1 Associated natural gas and LNG specifications

479 Table 2

PRICO process variable constraints

480 Table 3

Nitrogen expander process variable constraints

481 Table 4

The optimal solution of the PRICO process

482 Table 5

The optimal solution of the nitrogen expander process

483 Table 6

Feed condition and optimal design for the points shown in Fig. 6

484 Table 7

Feed condition and optimal design for the points shown in Fig. 9

\section{List of figure captions}

487 Fig. 1 PRICO process flow diagram

488 Fig. 2 Nitrogen single-expander process

489 Fig. 3 The sample region for the flexibility analysis

490 Fig. 4 (a) The temperature of the natural gas after the MHEX, and (b) The required cooling load for each feed sample

Fig. 5 the flexible region for the optimal PRICO process

Fig. 6 (a)The refrigerant flowrate and (b) power consumption contours for the PRICO flexible region Fig. 7 n-butane content in the mixed-refrigerant for the feasible region of the PRICO process

Fig. 8 the flexible region for the optimal nitrogen expander process

Fig. 9 (a) The refrigerant flowrate and (b) power consumption contours for the nitrogen expander flexible region 